Article - Biological and Applied Sciences

\title{
PI3K/Akt Signaling Involved with Osteoinductive Effects of Achatina fulica Mucus
}

\author{
Fahsai Kantawong ${ }^{*}$ \\ https://orcid.org/0000-0003-0323-3021 \\ Thananat Jearasakwattana ${ }^{2}$ \\ https://orcid.org/0000-0001-9253-8542
}

Alisa Nira ${ }^{3}$

https://orcid.org/0000-0002-6401-612X

Jumaila Chewae ${ }^{1}$

https://orcid.org/0000-0001-8799-798X

Phusanisa Sajjamongkol ${ }^{1}$

https://orcid.org/0000-0003-1863-6464

\section{Pajaree Phothong ${ }^{1}$}

https://orcid.org/0000-0003-4673-6948

\section{Teerasak E-kobon ${ }^{2,4}$}

https://orcid.org/0000-0002-3919-9841

\section{Pramote Chumnanpuen 3,4 \\ https://orcid.org/0000-0003-3072-1733}

${ }^{1}$ Chiang Mai University, Faculty of Associated Medical Sciences, Department of Medical Technology, Chiang Mai, Thailand; 'Kasetsart University, Faculty of Science, Department of Genetics, Bangkok, Thailand; ${ }^{3}$ Kasetsart University, Faculty of Science, Department of Zoology, Bangkok, Thailand; ${ }^{4}$ Kasetsart University, Computational Biomodelling Laboratory for Agricultural Science and Technology, Bangkok, Thailand

Received: 2019.04.30; Accepted: 2019.08.13

*Correspondence: Fahsai.k@cmu.ac.th; Tel.: +66-53-935085 (F.K.)

\section{HIGHLIGHTS}

- Mucus of $A$. fulica possesses osteoinductive property.

- The osteoinductive property of $A$. fulica mucus involves with PI3K signaling.

- Mucus of $A$. fulica enhances bone marker gene expression.

Abstract: Mesenchymal stem cells and osteoblasts play important roles in bone formation. Achatina fulica mucus presented the property of osteoinduction. This study aimed to examine the effects of $A$. fulica mucus on human mesenchymal stem cell (hMSC) and human fetal osteoblastic cell line (HFOB) differentiation. The 
integrated effects of $A$. fulica mucus and polycaprolactone (PCL) on the differentiation of hMSCs were tested. The cell viability of hMSCs treated with $A$. fulica mucus was investigated by the MTT assay. The cell mineralization was observed by Alizarin Red $S$ staining, the gene expression was investigated using RTPCR, and the PI3K activation was studied using flow cytometry. The results indicated that $A$. fulica mucus induced osteogenic differentiation in hMSCs and HFOBs by upregulation of the osteogenic markers; osteopontin (OPN) and osteocalcin (OCN). The results of the Alizarin Red S staining indicated that $A$. fulica mucus supported mineralization in both hMSCs and HFOBs. The hMSCs cultured on PCL supplemented with $A$. fulica mucus showed significantly increased RUNX2 and OPN expressions. A. fulica mucus was observed to increase PI3K activation in hMSCs. The findings of this study suggested that $A$. fulica mucus and biomaterials could be applied together for use in bone regeneration in the future.

Keywords: Achatina fulica; polycaprolactone; PI3K/Akt; glycosaminoglycan

\section{INTRODUCTION}

The giant African snail (Achatina fulica) is a large terrestrial gastropod which had its origin in Central and South Africa. The mucus of this snail contained mucopolysaccharides (mucin), glycoproteins (achacin and achatinin), glycosaminoglycans (acharan sulfate), proteoglycans, minerals, and peptides (achatinin-AF) [13]. Previous studies found that the mucus of $A$. fulica inhibited the growth of bacteria and cancer cells $[4,5]$. The mucus of this snail also had an intriguing role in wound healing and shell repairing after damaging of the shell $[6,7]$. A previous study, by Harti et al., found that a combination of $A$. fulica mucus and chitosan (at a ratio of 1:2) was effective in wound healing in mice [8]. Recently, Kantawong et al. (2016) demonstrated that A. fulica mucus enhanced mineralization in dental pulp cells (DPCs) [9]. Although, the DPCs contained mesenchymal stem cell population, the major population were fibroblasts which also responded to the induction so the expressions of OPN and OCN were slightly increased. To exclude the result from fibroblasts, A. fulica mucus was applied to hMSCs and HFOB. It was well-established that hMSCs had the ability to differentiate into multiple cell lineages including osteoblasts, chondrocytes, and adipocytes [10]. These properties of snail mucus have not been proven in hMSCs and HFOBs. This study demonstrated that $A$. fulica mucus could induce bone differentiation in hMSCs and HFOBs. Osteoblasts are presented in the inner layer of the periosteum [11], and it would be invasive to isolate them from the bones [12]. It is possible to isolate hMSCs from various tissue sources such as skin, adipose tissue, blood, and bone marrow [13, 14].

Furthermore, the lowest concentrations of mucus that still provided the osteoinduction effects was investigated to achieve the highest outcomes with less adverse effects such as inflammation. Moreover, $\mathrm{PCL}$ and $A$. fulica mucus were used in combination to investigate the bone differentiation of hMSCs. In tissue engineering, the use of biomaterials was necessary for cell proliferation and differentiation [15]. Biomaterials used for bone tissue engineering should have osteoinduction, osteoconduction, and osteointegration properties [16].

PCL is a bioresorbable polymer with potential applications for bone regeneration, and it has shown compatibility with osteoblasts [17]. PCL together with $A$. fulica mucus supplementation can serve as an environment for cell proliferation and differentiation which could be used in cell therapy and tissue engineering. The screening test of PI3K activation was performed using flow cytometry. Moreover, the purification of acharan sulfate to use in biomedical sciences could be performed in the future. The aims of this study were (1) to determine whether the use of $A$. fulica mucus supports the formation of mineralization nodules in osteoblasts and mesenchymal stem cells or not, (2) to determine whether the use of $A$. fulica mucus together with PCL is effective for applications in tissue engineering, and (3) to study the signaling pathway involved with the osteoinduction effect of $A$. fulica mucus.

\section{MATERIAL AND METHODS}

\section{Materials}

Immortalized hMSCs was purchased from Health Sciences Research Resource Bank, Osaka, Japan. Human fetal osteoblast cell line (HFOB1.19, CRL NO.11372) was purchased from ATCC. Dulbecco's modified Eagle's medium (DMEM) was purchased from Gibco. Polycaprolactone (PCL) was purchased from Sigma-Aldrich; UK. NucleoSpin® RNA II kit was purchased from Macherey-Nagel. SYBR Green Mastermix (SensiFAST SYBR ${ }^{\circledR}$ No-ROX Kit) was purchased from Bioline. cDNA was synthesized using ReverTra Ace ${ }^{\circledR}$ qPCR RT Master Mix from Toyobo. Muse ${ }^{\text {TM }}$ PI3K Activation Dual Detection Kit was purchased from Merck 
Millipore. Hot air oven was from Memmert, Germany. Inverted microscope (Nikon ECLIPSE TS 100) was from Nikon Corp. Japan.

\section{Preparation of snail mucus}

Mucus of $A$. fulica was prepared as previously described [9]. Briefly, the snail mucus samples were collected from adult $A$. fulica by mild intermittent irritation in an ultrasonicating bath for 5 rounds of $15 \mathrm{sec}$ at $30^{\circ} \mathrm{C}$. After each round of mild intermittent irritation, the snails were taken out and the mucus was eluted with $1 \mathrm{~mL}$ of distilled water for $1 \mathrm{~min}$. All of the collected mucus was vortex mixed and concentrated by freezedrying. The lyophilized mucus was kept at $-20^{\circ} \mathrm{C}$ until use.

\section{Cytotoxicity of $\boldsymbol{A}$. fulica mucus on hMSCs}

The hMSCs passage 10, were seeded into 24-well plates at a density of $1.5 \times 10^{4}$ cells/well. The cells were allowed for attachment for $24 \mathrm{~h}$ in complete DMEM (DMEM High Glucose supplemented with $10 \%$ fetal bovine serum, 100 units $/ \mathrm{mL}$ penicillin and $100 \mu \mathrm{g} / \mathrm{mL}$ streptomycin) at $37^{\circ} \mathrm{C}$ with $5 \% \mathrm{CO}_{2}$. The A. fulica mucus was diluted in complete DMEM to the concentrations of $9.375 \mu \mathrm{g} / \mathrm{mL}, 18.75 \mu \mathrm{g} / \mathrm{mL}, 37.5 \mu \mathrm{g} / \mathrm{mL}, 75$ $\mu \mathrm{g} / \mathrm{mL}$, and $150 \mu \mathrm{g} / \mathrm{mL}$. The medium was discarded before replacing with complete DMEM supplemented with the $A$. fulica mucus $\left(0.5 \mathrm{~mL} /\right.$ well). Cell culture was maintained at $37^{\circ} \mathrm{C}$ with $5 \% \mathrm{CO}_{2}$ for $48 \mathrm{~h}$. The medium was discarded and replaced with $0.5 \mathrm{~mL}$ of MTT reagent dissolved in complete DMEM $(0.5 \mathrm{mg} / \mathrm{mL})$. The reactions were incubated at $37^{\circ} \mathrm{C}$ with $5 \% \mathrm{CO}_{2}$ for $2 \mathrm{~h}$. The MTT-supplemented complete DMEM was discarded and replaced with $1 \mathrm{~mL}$ of DMSO before incubating on a shaker for $15 \mathrm{~min}$. The absorbance of the formazan product was measured at $540 \mathrm{~nm}$ and $630 \mathrm{~nm}$ by a UV-Vis spectrophotometer. The assays were carried out in triplicate for each concentration for statistical analysis, and the \%viability was calculated in comparison with the control.

\section{Treatment of hMSCs with A. fulica mucus}

The hMSCs were seeded in 6-well plates at a density of $2 \times 10^{4}$ cells/well, and the cells were allowed for attachment for $24 \mathrm{~h}$ in complete DMEM at $37^{\circ} \mathrm{C}$ with $5 \% \mathrm{CO}_{2}$. On the next day, the medium was discarded and replaced with $2 \mathrm{~mL} / \mathrm{well}$ of the mucus-supplemented complete DMEM $(150 \mu \mathrm{g} / \mathrm{mL})$. Cells cultured in complete DMEM was used as controls. The cells were maintained at $37^{\circ} \mathrm{C}$ with $5 \% \mathrm{CO}_{2}$ for 18 days to allow cell proliferation and differentiation. The media were replaced every 3 days.

\section{Treatment of HFOBs with A. fulica mucus}

HFOBs (passage 11) were seeded into 6-well plates at a density of $5.0 \times 10^{4}$ cells/well. The cells were allowed for attachment for $24 \mathrm{~h}$ in complete DMEM at $37^{\circ} \mathrm{C}$ and $5 \% \mathrm{CO}_{2}$. The complete DMEM was discarded and replaced with mucus-supplemented complete DMEM $(50 \mu \mathrm{g} / \mathrm{mL})$ at $4 \mathrm{~mL} /$ well. The cell culture was maintained at $37^{\circ} \mathrm{C}$ in a $5 \% \mathrm{CO}_{2}$ incubator for 8 days. The assays were performed in triplicate for statistical analysis.

\section{Cell morphology and mineralization assays}

Cell morphology was observed by staining with Coomassie Brilliant Blue and mineralization was observed by Alizarin Red S staining. Briefly, the cells were fixed with 4\% formaldehyde for 5-10 min and stained with Coomassie Brilliant Blue or $0.5 \%$ Alizarin Red S (pH 4.2) for 5 min. The stain was removed and the cells were rinsed with tap water before visualizing under an inverted microscope. The mineralized nodules were counted and reported as the number of nodules per well in comparison with that of the control group which was cultured in complete DMEM. The assays were performed in triplicate for statistical analysis.

\section{Gene expression of bone differentiation marker}

Both hMSCs and HFOBs were cultured for the desired periods. The culture medium was discarded and phosphate buffer saline was added to wash the cells. Then, the RNA was extracted using a NucleoSpin® RNA II kit. The amount of total RNA was quantified using a NanoDrop 2000 spectrophotometer (Thermo Scientific). The genomic DNA was eliminated by adding a DNase reaction mixture into the total RNA $\left(1 \mu \mathrm{L}\right.$ DNAse $/ 10 \mu \mathrm{L}$ RNA) and then incubating at $37^{\circ} \mathrm{C}$ for $10 \mathrm{~min}$. cDNA was synthesized using ReverTra 
Ace $^{\circledR}$ qPCR RT Master Mix, and the reverse transcription reaction was performed in an Eppendorf Mastercycler ${ }^{\circledR}$. RT-PCR was performed using a SYBR Green Mastermix. cDNA was diluted to the dilution of $1: 5$, and PCR reaction was prepared to a total volume of $10 \mu \mathrm{L}$ and then analyzed by real-time PCR (LightCycler 480). Relative quantification was performed using the LightCycler ${ }^{\circledR} 480$ software 1.5. Glyceraldehyde-3-phosphate dehydrogenase (GAPDH) and actin were used as the reference genes. The list of primers was shown in the $5^{\prime}$ to $3^{\prime}$ orientation. Primers sequences used in this this study were shown in the following details; OPN: F: 5-GGACAGCCAGGACTCCATTG-3, R: 5-TGTGGGGACAACTGGAGTGAA-3, OCN: F: 5-GCAAGTAGCGCCAATCTAGG-3, R: 5-GCTTCACCCTCGAAATGGTA-3, RUNX2: F: 5GATGACACTGCCACCTCTGA-3, R: 5-GACTGGCGGGGTGTAAGTAA-3, Actin: F: 5AGAAAATCTGGCACCACA-CC-3, R: 5-AGAGGCGTACAGGGATAGCA-3, GAPDH: F: 5AAGGGCTCATGACCACAGTC-3, R: 5-GGATGACCTTGCCCACAG-3.

\section{Effect of $\boldsymbol{A}$. fulica mucus and PCL on mesenchymal stem cell growth}

Polycaprolactone (PCL) beads were washed with distilled water, followed by washing with $70 \%$ ethanol and air-drying at room temperature. The PCL beads were placed in between two clean glass plates and tightly clamped before incubating in a hot air oven at $70^{\circ} \mathrm{C}$ for about $1-2 \mathrm{~h}$. The melted PCL in the glass plates was left at room temperature to cool down until the PCL turned into a white PCL sheet. The glass plates were disassembled and the PCL was cut into a circular shape with a diameter of $2 \mathrm{~cm}$. The PCL sheets were placed in 6-well culture plates and then sterilized with $70 \%$ ethanol for $15 \mathrm{~min}$. The PCL substrates were washed with sterile water for 15 min 3 times. The PCL sheets were equilibrated in complete DMEM for $48 \mathrm{~h}$ before use in the cell culture.

For short-term study, the hMSCs (passage 10) were seeded into 6-well plates at a density of $5.0 \times 10^{4}$ cells/well. The cells were allowed to attach for $24 \mathrm{~h}$ in complete DMEM at $37^{\circ} \mathrm{C}$ and $5 \% \mathrm{CO}_{2}$. The complete DMEM was discarded and replaced with mucus-supplemented complete DMEM $(50 \mu \mathrm{g} / \mathrm{mL})$ at $5 \mathrm{~mL} / \mathrm{well}$ and the cells were cultured for 5 days.

For long-term study, the hMSCs (passage 10) were seeded into 6-well plates at a density of $5.0 \times 10^{4}$ cells/well. The cells were allowed to attach for $24 \mathrm{~h}$ in complete DMEM at $37^{\circ} \mathrm{C}$ and $5 \% \mathrm{CO}_{2}$. The complete DMEM was discarded and replaced with mucus-supplemented complete DMEM $(25 \mu \mathrm{g} / \mathrm{mL}$ or $50 \mu \mathrm{g} / \mathrm{mL})$ at $5 \mathrm{~mL} /$ well. The cell culture was maintained at a temperature of $37^{\circ} \mathrm{C}$ in a $5 \% \mathrm{CO}_{2}$ incubator for 14 days. Each of the concentration assays was performed in triplicate for statistical analysis.

\section{PI3K activation assay}

The hMSCs (passage 12) $2 \times 10^{5}$ cells were seeded onto a tissue culture dish, and the cells were left in an incubator for $24 \mathrm{~h}$. The medium was discarded and replaced with mucus-supplemented complete DMEM $(35 \mu \mathrm{g} / \mathrm{mL})$ at $5 \mathrm{~mL} /$ well. The cell culture was maintained at a temperature of $37^{\circ} \mathrm{C}$ in a $5 \% \mathrm{CO}_{2}$ incubator for $5 \mathrm{~h}, 12 \mathrm{~h}$, and $48 \mathrm{~h}$. PI3K activation was performed using the Muse ${ }^{\mathrm{TM}}$ PI3K Activation Dual Detection Kit. The experiment at $5 \mathrm{~h}$ was performed at once. The experiments at $12 \mathrm{~h}$ and $48 \mathrm{~h}$ were carried out in triplicate to meet the requirement for statistical analysis.

\section{Statistical analysis}

All of the studies were conducted at least three times and the results analyzed by one-way ANOVA were presented as Mean \pm SD and $95 \%$ confidence interval $(P \leq 0.05)$ was used to determined significance of the test results.

\section{RESULTS}

\section{Cytotoxicity of $\boldsymbol{A}$. fulica mucus on hMSCs}

Human mesenchymal stem cells (hMSCs) were grown in the medium supplemented with different concentrations of $A$. fulica mucus for $48 \mathrm{~h}$. The MTT assay showed that the concentration of complete DMEM supplemented with the $A$. fulica mucus at $75 \mu \mathrm{g} / \mathrm{mL}$ and $150 \mu \mathrm{g} / \mathrm{mL}$ significantly affected the cell viability compared to the control group at $\mathrm{P}<0.05$ and $\mathrm{P}<0.01$, respectively (see Figure 1). A concentration of 150 $\mu \mathrm{g} / \mathrm{mL}$ was used in the next experiment because this concentration displayed $\mathrm{IC}_{20}$. 


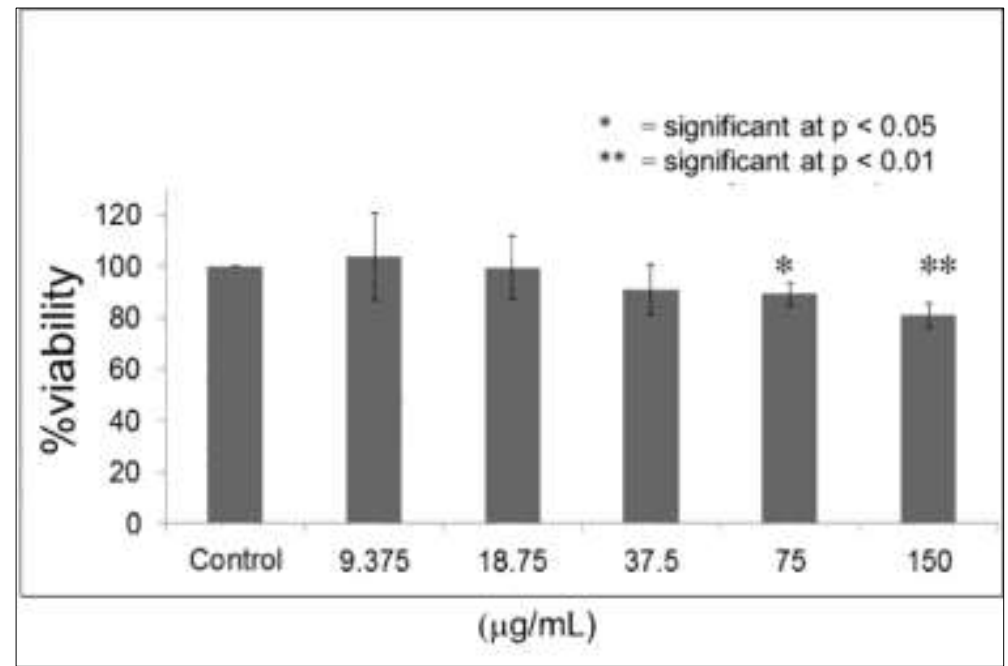

Figure 1: The MTT assay indicated that $A$. fulica mucus at the concentrations of $75 \mu \mathrm{g} / \mathrm{mL}$ and $150 \mu \mathrm{g} / \mathrm{mL}$ had an effect on hMSC viability at $48 \mathrm{~h}\left({ }^{*} \mathrm{P}<0.05\right.$ and ${ }^{* *} \mathrm{P}<0.01$, respectively).

\section{A. fulica mucus enhances calcium deposition in hMSCs and HFOBs}

Cell staining with Coomassie Brilliant Blue showed that the hMSCs grown in complete DMEM supplemented with $150 \mu \mathrm{g} / \mathrm{mL}$ of $A$. fulica mucus showed less density of cells with osteoblast-like shape compared to those cultured in normal complete DMEM (see Figure 2A \& 2B).

$A$. fulica mucus induced cell differentiation and when cell differentiation occurred, cells decreased proliferation so less cell density was observed in $A$. fulica mucus treated group. The deposition of calcium was observed to be increased in the cells grown in the medium supplemented with $A$. fulica mucus compared with the cells grown in normal medium (see Figure 2C \& 2D).

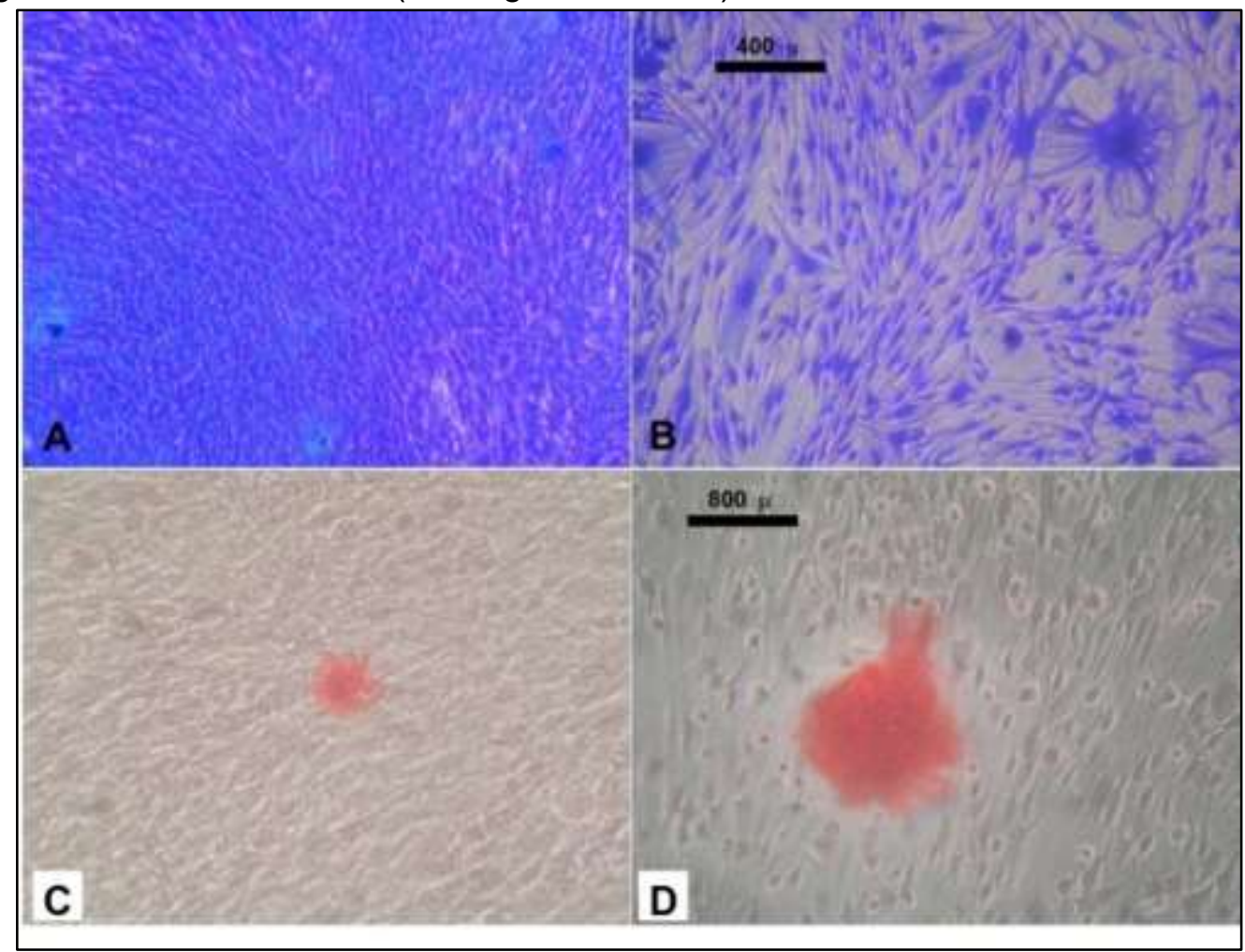

Figure 2: (A) Morphology of hMSCs cultured in complete DMEM for 18 days. (B) Morphological changes of hMSCs cultured in complete DMEM supplemented with $150 \mu \mathrm{g} / \mathrm{mL}$ of $A$. fulica mucus for 18 days. (C) The Alizarin Red $S$ staining of hMSCs cultured in complete DMEM for 18 days. (D) The Alizarin Red S staining of hMSCs cultured in complete DMEM supplemented with $150 \mu \mathrm{g} / \mathrm{mL}$ of $A$. fulica mucus for 18 days.

Then, a smaller concentration of $A$. fulica mucus $(50 \mu \mathrm{g} / \mathrm{mL})$ was used to investigate the mineralization in the HFOBs. HFOBs cultured in mucus supplemented complete DMEM $(50 \mu \mathrm{g} / \mathrm{mL})$ showed a higher degree 
of cell mineralization when observed under a microscope (see Figure 3A\&B). The numbers of mineralized nodules were counted and it was demonstrated that cells in the mucus treated group formed more mineralized nodules compared to the control group (see Figure 3C).

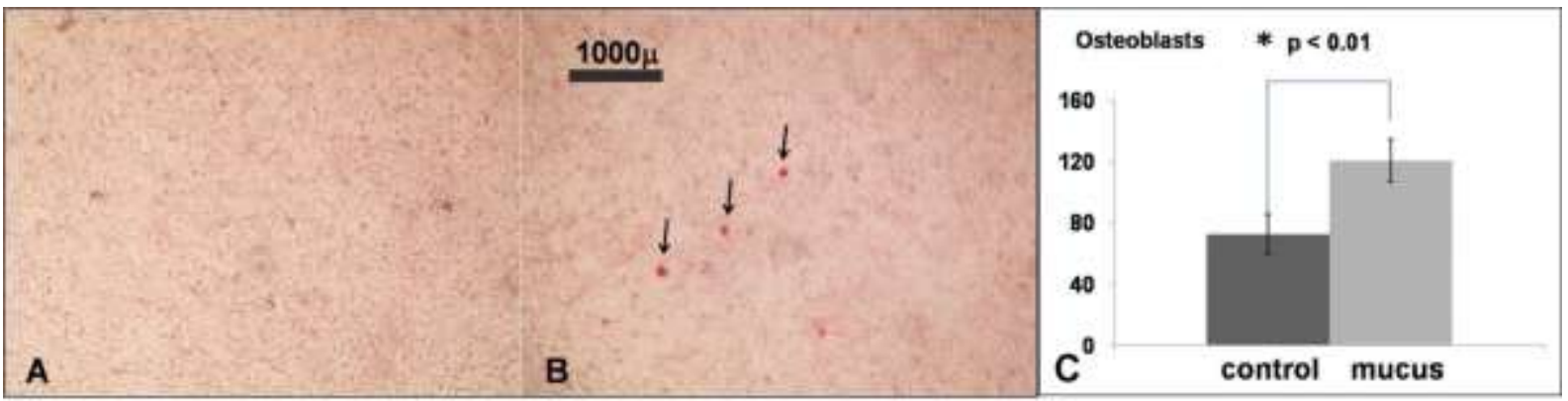

Figure 3: (A) The Alizarin Red $S$ staining of hFOBs cultured in complete DMEM for 8 days. (B) The Alizarin Red $S$ staining of hFOBs cultured in complete DMEM containing $50 \mu \mathrm{g} / \mathrm{mL}$ of $A$. fulica mucus for 8 days. (C) The hFOBs supplemented with $50 \mu \mathrm{g} / \mathrm{mL}$ of $A$. fulica mucus showed a significantly higher number of mineralization nodules compared to the control group $(P<0.01)$.

\section{A. fulica mucus induces expression of bone markers in hMSCs}

The relative gene expression of the osteoblast markers, OCN and OPN, were as shown in Figure 4A (see Figure 4A). Both the genes were significantly upregulated in the hMSCs treated with $150 \mu \mathrm{g} / \mathrm{mL}$ of $A$. fulica mucus at 18 days compared with the control, using GAPDH as the reference gene. OCN was found to be increased 1.6 folds $(P=0.002)$, and OPN was found to be increased 21 folds $(P=0.03)$ compared to the control.

\section{A. fulica mucus induces expression of bone markers in HFOBs}

The HFOBs cultured in mucus supplemented complete DMEM $(50 \mu \mathrm{g} / \mathrm{mL})$ presented increased expression of the OPN gene compared to the control group $(P<0.05)$, using GAPDH and actin as the reference genes (see Figure 4B). Osteoblasts are considered as lineage committed, so only $50 \mu \mathrm{g} / \mathrm{mL}$ could induce bone formation within 8 days. However, in the real situation, isolation of osteoblasts from bones is practically difficult.

\section{Expression of RUNX2 and OPN in hMSCs on PCL sheet}

Mesenchymal stem cells are widely used for studies in tissue engineering and cell therapy as these stem cells can be obtained from the bone marrow, blood, or pulp tissues, which is more practically useful in the medical field. A study of the mesenchymal stem cells cultured on PCL sheets in complete DMEM supplemented with $A$. fulica mucus was performed.

Figure 4C indicates that the hMSCs cultured on the PCL sheets and supplemented with $50 \mu \mathrm{g} / \mathrm{mL}$ of $A$. fulica for 5 days had increased expression of RUNX2 compared to the hMSCs cultured on the PCL sheets supplemented with normal medium $(P<0.001)$. In the long-term culture, the hMSCs cultured on the PCL sheets and supplemented with $50 \mu \mathrm{g} / \mathrm{mL}$ of $A$. fulica for 14 days was found to have increased expression of OPN compared to the hMSCs cultured on the PCL sheets supplemented with $25 \mu \mathrm{g} / \mathrm{mL}$ of $A$. fulica $(\mathrm{P}<$ $0.001)$. A. fulica at the concentration of $25 \mu \mathrm{g} / \mathrm{mL}$ did not show any osteoinductive effect on the hMSCs cultured on the PCL sheets supplemented with the normal medium. 


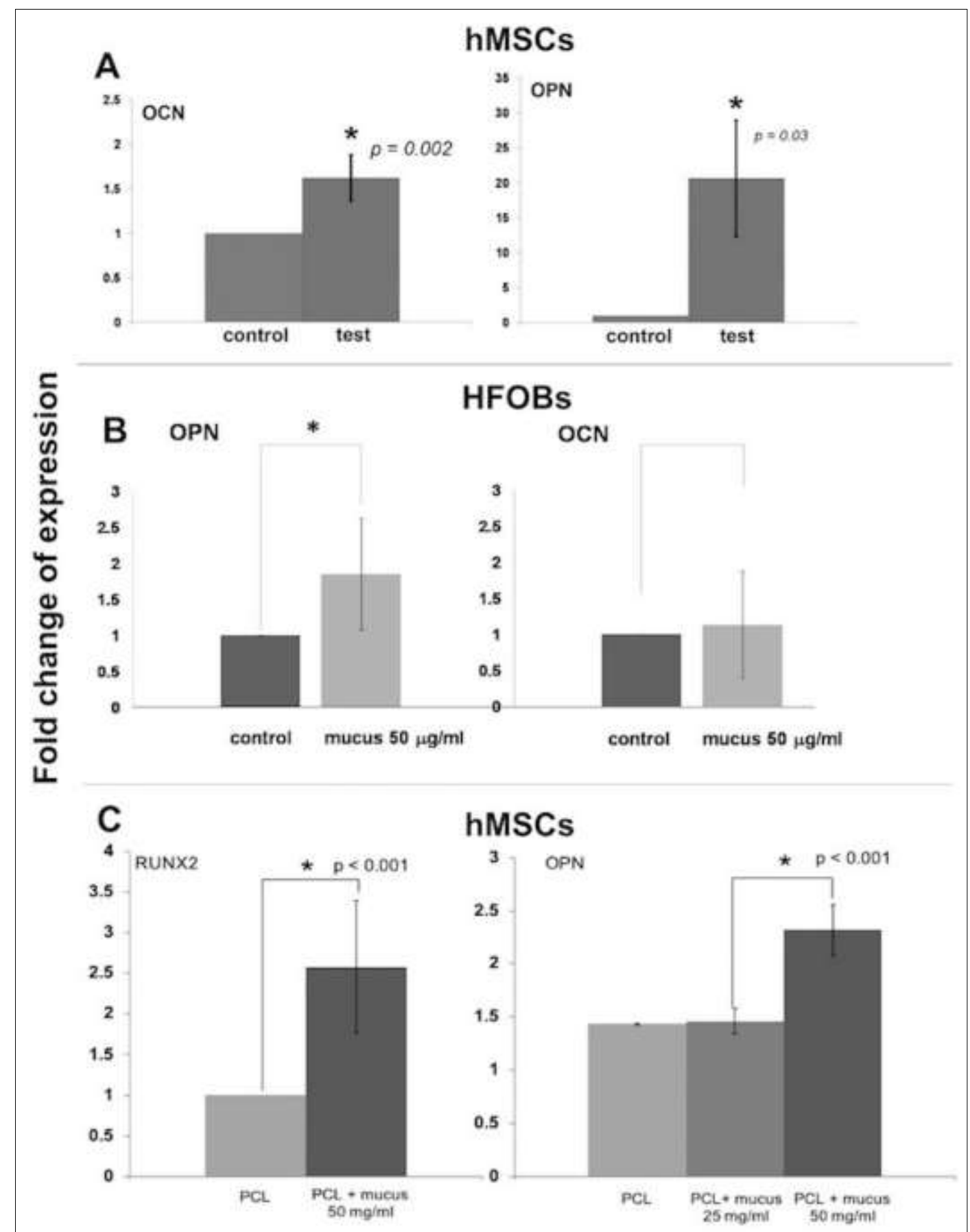

Figure 4: (A) OCN and OPN expressions of hMSCs cultured in a medium supplemented with $150 \mu \mathrm{g} / \mathrm{mL}$ of $A$. fulica mucus were higher than control group at 18 days culture. The significance levels of the OCN and the OPN expressions were determined at $\mathrm{P}=0.002$ and $\mathrm{P}=0.03$, respectively. (B) The OPN expressions of HFOBs cultured in a medium supplemented with $50 \mu \mathrm{g} / \mathrm{mL}$ of $A$. fulica mucus was higher than control at 8 days culture $\left({ }^{*} P=0.012\right)$. No significance of OCN expression was observed. (C) When hMSCs were cultured on PCL sheets, increased expressions of the RUNX2 gene $\left({ }^{*} \mathrm{P}<0.001\right)$ was observed in $\mathrm{hMSC}$ supplemented with $50 \mu \mathrm{g} / \mathrm{mL}$ A. fulica mucus at 5 days culture. Increased expression of OPN gene ( ${ }^{*} \mathrm{P}<0.0001$ ) was observed in the hMSCs supplemented with $50 \mu \mathrm{g} / \mathrm{mL}$ A. fulica mucus at 14 days. hMSCs supplemented with $25 \mu \mathrm{g} / \mathrm{mL}$ A. fulica mucus did not show significant OPN expression at 14 days.

\section{PI3K activation assay in hMSCs}

For PI3K we used $35 \mu \mathrm{g} / \mathrm{mL}$ because our previous study found that $15 \mu \mathrm{g} / \mathrm{mL}$ could drive dental pulp cells to have mineral accumulation, however, in this study when we used $15 \mu \mathrm{g} / \mathrm{mL}$ we could not see PI3K activation. It was possible that the activation depended on cell type and the quality of $A$. fulica mucus in each lot. The result showed that $A$. fulica mucus at the concentration of $35 \mu \mathrm{g} / \mathrm{mL}$ could increase the percentage 
of phosphor-Akt at $5 \mathrm{~h}$ of treatment $(4.40 \%)$ compared to the time-related control (1.90\%) (see Figure $5 \mathrm{~A} \&$ 5B). Triplicate of the time course study were performed at $12 \mathrm{~h}$ and $48 \mathrm{~h}$ (see Figure 5C \& 5D).

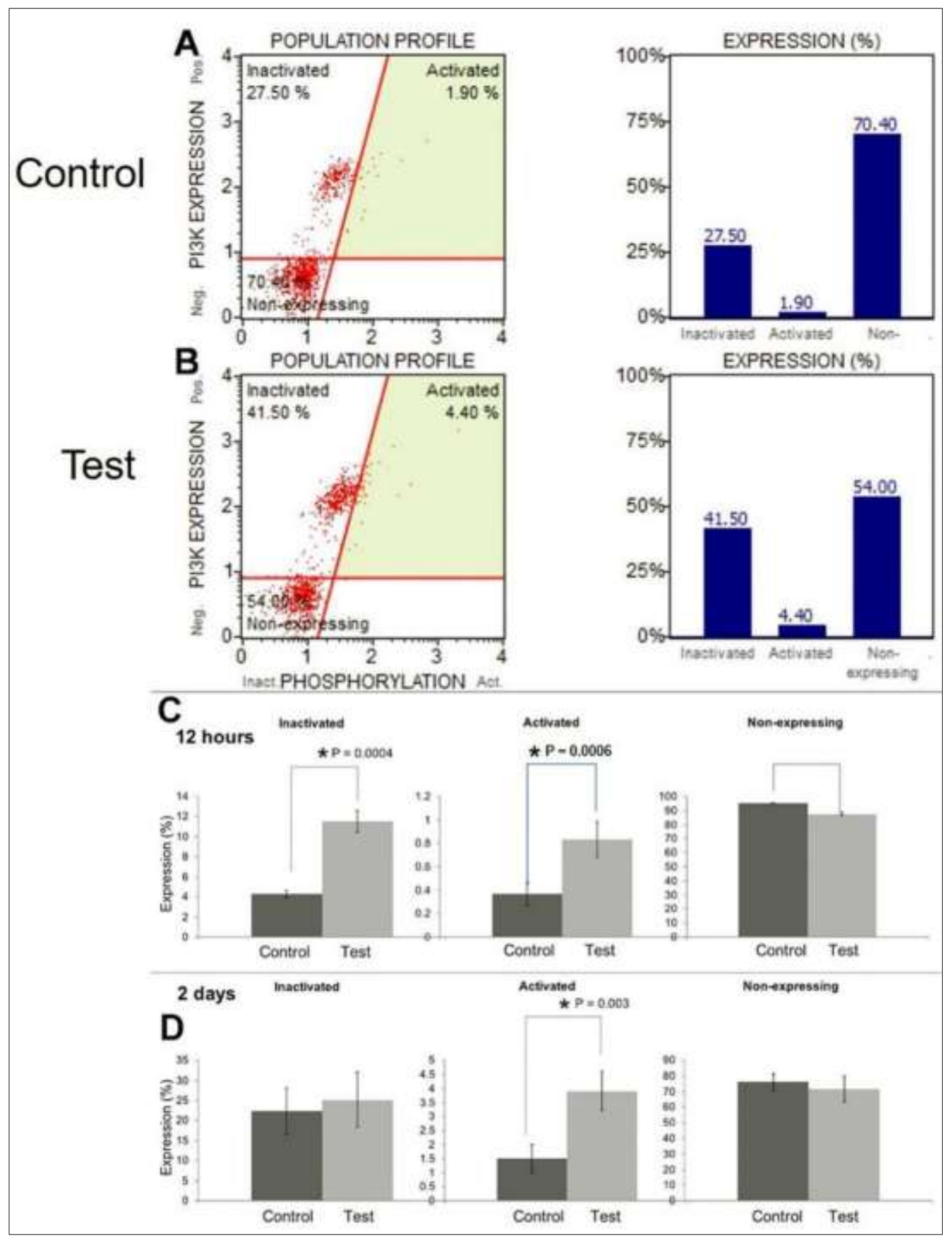

Figure 5: (A) PI3K activation in control group $=1.90 \%$. (B) PI3K activation in the $\mathrm{hMSC}$ cultured in mucus $35 \mu \mathrm{g} / \mathrm{mL}$ for $5 \mathrm{~h}=4.40 \%$. (C) PI3K activation in the hMSCs cultured in complete DMEM supplemented with snail mucus for $12 \mathrm{~h}$ was higher than the time-correlated control groups. (D) PI3K activation in the hMSCs cultured in complete DMEM supplemented with snail mucus for $48 \mathrm{~h}$ was higher than the time-correlated control groups.

\section{DISCUSSION}

A concentration of $150 \mu \mathrm{g} / \mathrm{mL}$ was chosen for the hMSCs treatment because the appropriate concentration for cell differentiation should give $\mathrm{IC}_{20}$ (80\% viability). Actually, the MTT assay was performed for the HFOBs and the result was shown that no cytotoxicity was found for the same range of mucus concentration used for the hMSCs (data not shown). The concentration $50 \mu \mathrm{g} / \mathrm{mL}$ was chosen for the HFOBs 
treatment because the HFOBs were already committed to be bone cells so we used smaller concentration just for the induction of mineralization.

This study showed that the hMSCs grown in a medium supplemented with $A$. fulica mucus could differentiate into osteoblast-like cells compared to the hMSCs grown in the normal medium. The biochemical composition of $A$. fulica mucus could stimulate the formation of calcium nodules. Acharan sulfate, a glycosaminoglycan found in A. fulica, has a major disaccharide repeating unit structurally related to both heparin and heparan sulfate [18]. Previous studies have suggested that glycosaminoglycan enhanced osteogenic differentiation [19]. Mathews et al. have reported that hyaluronic acid provided the most favorable condition for osteoblast differentiation and bone matrix synthesis [20]. Hyaluronic acid was incorporated in the biomimetic tripolymer scaffolds that supported the proliferation and differentiation of hMSCs [21].

It was shown that a reduction in the concentration of $A$. fulica mucus could stimulate mineralization in the HFOBs compared to the amount used for the hMSCs. HFOBs showed different patterned of mineralization compared to hMSCs. The hMSCs formed a few big mineralized nodules while the HFOBs formed many small mineralized nodules so nodule counting may not be suitable for the hMSCs. The quantification was not performed because cells grown in the medium supplemented with $A$. fulica mucus showed large mineralized nodules but presented less density of cells compared with the cells grown in normal medium. Less density of cells caused less optical density (OD) when compared to much higher cell density in the control group.

Runt-related transcription factor 2 (RUNX2) was a transcription factor that was essential for osteoblast differentiation and maturation [22]. RUNX2 enhanced the proliferation of osteoblast progenitors and enhanced the proliferation of mesenchymal cells and induced their commitment into osteoblast lineage cells [23]. RUNX2 expression increased in stages of osteoblast differentiation. RUNX2 bound to the OCN promoter and expressed in osteochondral progenitors to stimulate osteoblastic differentiation at the early stage, and prevented osteoblastic differentiation at the late stage [24].

The concentrations of $A$. fulica mucus at $25 \mu \mathrm{g} / \mathrm{mL}$ and $50 \mu \mathrm{g} / \mathrm{mL}$ were used to observe the dose dependent effects. Real-time PCR showed that the PCL sheets supplemented with $A$. fulica mucus at 50 $\mu \mathrm{g} / \mathrm{mL}$ could promote the RUNX2 expression in hMSCs at 5 days culture and enhanced the OPN expression significantly at 14 days culture. However, the lower concentration of $25 \mu \mathrm{g} / \mathrm{mL}$ was not observed to have any osteoinductive effect in the hMSCs culture on the PCL sheet. It was found that OPN expression increased significantly and OCN was just likely to increase without statistical significant. OCN was a late maker which could be detected later than OPN. OPN was a glycoprotein which was a main component of mineralized extracellular matrices of bones and teeth [25]. OPN expressed in pre-osteoblasts and mature osteoblasts while OCN expressed only in mature osteoblasts [26]. This might be the reason that only OPN expression was dominant in this study.

The result indicated that $A$. fulica mucus significantly increased the PI3K activation by increasing phosphor-Akt as shown that activated Akt was higher in the test group. Moreover, the mucus of $A$. fulica increased the number of cells that expressed Akt because the non-expressing cells in the test group were lesser than those of the control group (see Non-expressing). The osteoinductive effect of heparin and heparan sulfate has much to do with the PI3K/Akt signaling pathway [27]. PI3K signaling is important for the osteogenic differentiation of hMSCs $[28,29]$. Activation of PI3K signaling increased the phosphorylation of Akt at Ser473 [30]. The flow cytometry result revealed subtle and sustained activation of PI3K, which could be confirmed by observing the increased percentage of phosphor-Akt, which was slightly increased at $5 \mathrm{~h}$, $12 \mathrm{~h}$, and $48 \mathrm{~h}$. However, the percentage of non-expressing cells was higher in the control group, which implied that the cells treated with $A$. fulica mucus induced a higher level of Akt expression. The subtle and sustained activation of PI3K signaling was indicative of the benefit of $A$. fulica mucus treatment which did not dramatically change PI3K activity as happens in cancer state [31]. The further study about $A$. fulica mucus purification was continued in our laboratory.

\section{CONCLUSION}

The mucus of $A$. fulica induced the osteogenic differentiation of the hMSCs and HFOBs confirmed by microscopic observation of the mineralization nodules and morphological change of the hMSCs to osteocytelike shape, and by the increased expression of the osteogenic marker genes, OPN and OCN, in the hMSCs grown in the medium supplemented with the snail mucus. The use of PCL in combination with $A$. fulica mucus supplementation could induce mesenchymal stem cell differentiation. The integration effects between biomaterials and $A$. fulica mucus can be applied in tissue engineering of bones in the future. The osteoinduction effects of $A$. fulica mucus involved with PI3K/Akt signaling pathway. 
Funding: The authors acknowledge the financial support from the Faculty of Associated Medical Sciences, Chiang Mai University.

Acknowledgments: The authors would like to give special thanks to Prof. Kidoaki, Institute for Materials Chemistry and Engineering, Kyushu University, for providing hMSCs and Prof. Prachya Kongtawelert, Faculty of Medicine, Chiang Mai University, for providing HFOBs.

Conflicts of Interest: The authors declare no conflicting interests. The funders had no role in the design of the study; in the collection, analyses, or interpretation of data; in the writing of the manuscript, or in the decision to publish the results.

\section{REFERENCES}

1. Biswas C, Sinha D, Mandal C. Investigation on interaction of Achatinin, a 9-O-acetyl sialic acid-binding lectin, with lipopolysaccharide in the innate immunity of Achatina fulica snails. Mol Immunol. 20002000 Aug-Sep;37(1213):745-54. DOI: 10.1016/S0161-5890(00)00096-1

2. Ehara $T$, Kitajima S, Kanzawa N, Tamiya $T$, Tsuchiya $T$. Antimicrobial action of achacin is mediated by L-amino acid oxidase activity. FEBS Lett. 2002 Nov;531(3):509-12. DOI: 10.1016/s0014-5793(02)03608-6

3. Zhong J, Wang W, Yang X, Yan X, Liu R. A novel cysteine-rich antimicrobial peptide from the mucus of the snail of Achatina fulica. Peptides. 2013 Jan;39:1-5. DOI: 10.1016/j.peptides.2012.09.001

4. Ito S, Shimizu M, Nagatsuka M, Kitajima S, Honda M, Tsuchiya T, et al. High molecular weight lectin isolated from the mucus of the giant African snail Achatina fulica. Biosci Biotechnol Biochem. 2011;75(1):20-5. DOI: $10.1271 /$ bbb. 100389

5. E-Kobon T, Thongararm P, Roytrakul S, Meesuk L, Chumnanpuen P. Prediction of anticancer peptides against MCF-7 breast cancer cells from the peptidomes of Achatina fulica mucus fractions. Comput Struct Biotechnol J. 2016;14:49-57. PubMed PMID: 26862373. DOI: 10.1016/j.csbj.2015.11.005

6. Brieva A, Philips N, Tejedor R, Guerrero A, Pivel JP, Alonso-Lebrero JL, et al. Molecular basis for the regenerative properties of a secretion of the mollusk Cryptomphalus aspersa. Skin Pharmacol Physiol. 2008;21(1):15-22. DOI: 10.1159/000109084

7. Fleury C, Marin F, Marie B, Luquet G, Thomas J, Josse C, et al. Shell repair process in the green ormer Haliotis tuberculata: a histological and microstructural study. Tissue Cell. 2008 Jun;40(3):207-18. DOI: 10.1016/j.tice.2007.12.002

8. Harti A, Sulisetyawati S, Murharyati A, Oktariani M. The effectiveness of snail slime and chitosan in wound healing. Int J Pharm Med Biol Sci. 2016;5(1):76 - 80. DOI: 10.18178/ijpmbs.5.1.76-80

9. Kantawong F, Thaweenan P, Mungkala S, Tamang S, Manaphan R, Wanachantararak P, et al. Mucus of Achatina fulica stimulates mineralization and inflammatory response in dental pulp cells. Turkish Journal of Biology. 2016 2016;40(2):353-9. DOI: 10.3906/biy- 1505-29

10. Gamblin AL, Brennan MA, Renaud A, Yagita H, Lézot F, Heymann D, et al. Bone tissue formation with human mesenchymal stem cells and biphasic calcium phosphate ceramics: the local implication of osteoclasts and macrophages. Biomaterials. 2014 Dec;35(36):9660-7. DOI: 10.1016/j.biomaterials.2014.08.018

11. Dwek JR. The periosteum: what is it, where is it, and what mimics it in its absence? Skeletal Radiol. 2010 Apr;39(4):319-23. DOI 10.1007/s00256-009-0849-9

12. Fujita K, Roforth MM, Atkinson EJ, Peterson JM, Drake MT, McCready LK, et al. Isolation and characterization of human osteoblasts from needle biopsies without in vitro culture. Osteoporos Int. 2014 Mar;25(3):887-95. DOI: 10.1007/s00198-013-2529-9

13. Kuçi S, Kuçi Z, Latifi-Pupovci H, Niethammer D, Handgretinger R, Schumm $M$, et al. Adult stem cells as an alternative source of multipotential (pluripotential) cells in regenerative medicine. Curr Stem Cell Res Ther. 2009 May;4(2):107-17.

14. Malgieri A, Kantzari E, Patrizi MP, Gambardella S. Bone marrow and umbilical cord blood human mesenchymal stem cells: state of the art. Int J Clin Exp Med. 2010 Sep;3(4):248-69. PubMed PMID: 21072260.

15. Dhandayuthapani B, Yoshida Y, Maekawa T, Kumar D. Polymeric Scaffolds in Tissue Engineering Application: A Review. International Journal of Polymer Science. 2011 2011. DOI: 10.1155/2011/290602

16. Albrektsson T, Johansson C. Osteoinduction, osteoconduction and osseointegration. Eur Spine J. 2001 Oct;10 Suppl 2:S96-101. DOI: 10.1007/s005860100282

17. Ciapetti G, Ambrosio L, Savarino L, Granchi D, Cenni E, Baldini N, et al. Osteoblast growth and function in porous poly epsilon -caprolactone matrices for bone repair: a preliminary study. Biomaterials. 2003 Sep;24(21):3815-24. DOI: 10.1016/s0142-9612(03)00263-1 
18. Vieira TC, Costa-Filho A, Salgado NC, Allodi S, Valente AP, Nasciutti LE, et al. Acharan sulfate, the new glycosaminoglycan from Achatina fulica Bowdich 1822. Structural heterogeneity, metabolic labeling and localization in the body, mucus and the organic shell matrix. Eur J Biochem. 2004 Feb;271(4):845-54. DOI: 10.1111/j.1432-1033.2004.03989.x

19. Förster Y, Bernhardt R, Hintze V, Möller S, Schnabelrauch M, Scharnweber D, et al. Collagen/glycosaminoglycan coatings enhance new bone formation in a critical size bone defect - A pilot study in rats. Mater Sci Eng C Mater Biol Appl. 2017 Feb;71:84-92. DOI: 10.1016/j.msec.2016.09.071

20. Mathews S, Mathew SA, Gupta PK, Bhonde R, Totey S. Glycosaminoglycans enhance osteoblast differentiation of bone marrow derived human mesenchymal stem cells. J Tissue Eng Regen Med. 2014 Feb;8(2):143-52. DOI: 10.1002/term.1507

21. Mathews S, Bhonde R, Gupta PK, Totey S. Novel biomimetic tripolymer scaffolds consisting of chitosan, collagen type 1, and hyaluronic acid for bone marrow-derived human mesenchymal stem cells-based bone tissue engineering. J Biomed Mater Res B Appl Biomater. 2014 Nov;102(8):1825-34. DOI: 10.1002/jbm.b.33152

22. Komori T. Runx2, an inducer of osteoblast and chondrocyte differentiation. Histochem Cell Biol. 2018 Apr;149(4):313-23. DOI: 10.1007/s00418-018-1640-6

23. Kawane $T$, Qin X, Jiang Q, Miyazaki T, Komori H, Yoshida CA, et al. Runx2 is required for the proliferation of osteoblast progenitors and induces proliferation by regulating Fgfr2 and Fgfr3. Sci Rep. 2018 Sep;8(1):13551. DOI: 10.1038/s41598-018-31853-0

24. Shahi M, Peymani A, Sahmani M. Regulation of Bone Metabolism. Rep Biochem Mol Biol. 2017 Apr;5(2):73-82.

25. Singh A, Gill G, Kaur H, Amhmed M, Jakhu H. Role of osteopontin in bone remodeling and orthodontic tooth movement: a review. Prog Orthod. 2018 Jun;19(1):18. DOI: 10.1186/s40510-018-0216-2

26. Rutkovskiy A, Stensløkken KO, Vaage IJ. Osteoblast Differentiation at a Glance. Med Sci Monit Basic Res. 2016 Sep;22:95-106.

27. Ling L, Dombrowski C, Foong KM, Haupt LM, Stein GS, Nurcombe V, et al. Synergism between Wnt3a and heparin enhances osteogenesis via a phosphoinositide 3-kinase/Akt/RUNX2 pathway. J Biol Chem. 2010 Aug;285(34):26233-44. DOI: 10.1074/jbc.M110.122069

28. James AW. Review of Signaling Pathways Governing MSC Osteogenic and Adipogenic Differentiation. Scientifica (Cairo). 2013;2013:684736. DOI: 10.1155/2013/684736

29. Baker N, Sohn J, Tuan RS. Promotion of human mesenchymal stem cell osteogenesis by PI3-kinase/Akt signaling, and the influence of caveolin-1/cholesterol homeostasis. Stem Cell Res Ther. 2015;6:238. DOI: 10.1186/s13287015-0225-8

30. Lauzon MA, Drevelle O, Daviau A, Faucheux N. Effects of BMP-9 and BMP-2 on the PI3K/Akt Pathway in MC3T3E1 Preosteoblasts. Tissue Eng Part A. 2016 Sep;22(17-18):1075-85. DOI: 10.1089/ten.TEA.2016.0151

31. Miyakawa M, Tsushima T, Murakami H, Wakai K, Isozaki O, Takano K. Increased expression of phosphorylated p70S6 kinase and Akt in papillary thyroid cancer tissues. Endocr J. 2003 Feb;50(1):77-83.

(C) 2020 by the authors. Submitted for possible open access publication under the terms and conditions of the Creative Commons Attribution (CC BY NC) license (https://creativecommons.org/licenses/by-nc/4.0/). 